\title{
PEMANFAATAN QUANTUM DOT SEBAGAI DETEKTOR SINAR-X DALAM UPAYA MENGURANGI DOSIS PENYINARAN
}

\author{
Ida Bagus Gede Putra Pratama ${ }^{1}$
}

1) Badan Pengawas Tenaga Nuklir, DKI Jakarta, Indonesia, i.bagusgede @ bapeten.go.id

\begin{abstract}
ABSTRAK
Quantum Dot merupakan material semikonduktor dengan ukuran kurang dari $10 \mathrm{~nm}$ yang memiliki sifat khas yakni dapat memancarkan gelombang elektromagnetik pada panjang gelombang yang bervariasi bergantung dari ukuran partikelnya. Dengan sifat tersebut, Quantum Dot dimanfaatkan dalam beberapa bidang seperti untuk pencitraan biomedis, label dokumen hingga detektor. Dalam pencitraan yang memanfaatkan sinar-X, bahan fosfor umumnya digunakan sebagai transduser yang mengkonversi sinar-X menjadi cahaya tampak. Selain menggunakan bahan fosfor, sinar-X juga dapat dideteksi menggunakan semikonduktor. Pemanfaatan semikonduktor khususnya Quantum Dot juga dapat disandingkan dengan bahan fosfor sebagai detektor sinar-X. Beberapa penelitian menunjukkan bahwa dengan kombinasi antara bahan fosfor dengan Quantum Dot dapat menghasilkan peningkatan pendaran cahaya tampak yang dihasilkan oleh transduser tersebut.

Berkaitan dengan upaya optimisasi proteksi radiasi dalam pemanfaatan radiasi pengion yang memegang prinsip ALARA (As Low As Reasonably Achievable), maka adanya kombinasi bahan fosfor dan Quantum Dot sebagai detektor sinar-X dapat mendukung prinsip proteksi radiasi dengan mengurangi dosis radiasi yang diterima, baik untuk pasien, pekerja dan masyarakat. Peningkatan intensitas pendaran yang dihasilkan menunjukkan peningkatan efisiensi detektor dalam mengubah sinar-X menjadi cahaya tampak. Dengan efisiensi detektor fosfor-Quantum Dot yang lebih tinggi, maka dibutuhkan sinar-X dengan dosis yang lebih rendah untuk menghasilkan citra dengan kualitas yang sama dari hasil penyinaran menggunakan detektor fosfor biasa.
\end{abstract}

Kata kunci: Quantum Dot, Sinar-X, Detektor, Dosis radiasi, Optimisasi

\begin{abstract}
Quantum Dot is a semiconductor material with size less than $10 \mathrm{~nm}$. It has a characteristic that can emit electromagnetic waves at varying wavelengths depending on the size of the particle. With these properties, Quantum Dot is utilized in such areas as for biomedical imaging, document labels and also detectors. In imaging using X-rays, phosphorus materials are generally used as transducers that convert $X$ rays into visible light. In addition to using phosphorus materials, X-rays can also be detected using semiconductors. The utilization of semiconductors especially Quantum Dot can also be paired with phosphorus material as an X-ray detector. Several studies have shown that the combination of phosphorus with Quantum Dot can increase visible light emitted by the transducer.

In connection with the optimization efforts of radiation protection in the utilization of ionizing radiation which holds the principle of ALARA (As Low As Reasonably Achievable), the combination of phosphorus and Quantum Dot as an X-ray detector can support the principle of radiation protection by reducing the received radiation dose for patient, workers and society. The increase of the intensity of the resulting luminescence shows the increased efficiency of the detector in converting X-rays into visible light. With the higher efficiency of the phosphor-Quantum Dot detector, it takes a lower-dose of X-ray to produce the same quality image than radiation results using ordinary phosphorus detectors.
\end{abstract}

Key words: Quantum Dot, X-ray, Detector, Radiation Dose, Optimization

\section{PENDAHULUAN}

Quantum Dot (QD) merupakan material berjenis semikonduktor yang memiliki ukuran kurang dari $20 \mathrm{~nm}$. QD memiliki sifat khas yakni kemampuan untuk mengemisikan gelombang elektromagnetik dengan panjang gelombang yang bervariasi. Variasi panjang 
gelombang yang diemisikan bergantung terhadap ukuran dari QD tersebut [5].

QD telah banyak dimanfaatkan di berbagai bidang, baik untuk pencitraan biomedis, sel surya, label dokumen hingga detektor [1][2][5][6][7]. Berkaitan dengan pemanfaatan QD, deteksi sinar-X merupakan salah satu lingkup yang sangat memungkinkan dalam memanfaatkan QD. Selama ini sinar-X dideteksi dengan menggunakan bahan fosfor yang mengkonversi sinar-X menjadi cahaya tampak. Cahaya tampak tersebut yang kemudian dimanfaatkan untuk menghasilkan citra radiograf pada kertas film. Pada sistem radiografi diagnostik di bidang kesehatan, pencitraan dilakukan dengan memanfaatkan hasil konversi sinar-X menjadi cahaya tampak tersebut untuk bereaksi dengan kertas film. Selain menggunakan bahan fosfor, sinar-X juga dapat dideteksi menggunakan material semikonduktor. Mekanisme pencitraan dengan menggunakan semikonduktor, sama dengan menggunakan detektor berbahan fosfor. Sinar$\mathrm{X}$ yang berinteraksi dengan material semikonduktor akan dikonversi menjadi cahaya tampak sehingga dapat berinteraksi dengan kertas film.

Pemilihan jenis detektor untuk mengkonversi sinar- $\mathrm{X}$ menjadi cahaya tampak merupakan salah satu kondisi yang harus dipertimbangkan. Hal ini dikarenakan tidak semua semikonduktor memiliki kemampuan yang sama dalam mengkonversi sinar-X. Hal ini berkaitan dengan efisiensi detektor dalam mengkonversi sinar-X. Dibutuhkan efisiensi yang tinggi untuk dapat mengkonversi sinar-X lebih banyak untuk menjadi cahaya tampak.

Berkaitan dengan pemanfaatan radiasi pengion, IAEA dalam dokumen General Safety Requirement Part 3 menyebutkan dalam Requirement 11, bahwa "The government and the regulatory body shall establish and enforce requirements for optimization of protection and safety, and registrants and licensees shall ensure that protection and safety is optimized" [4]. Dalam dokumen Safety Fundamental IAEA, Principle 5: Optimization of protection menyebutkan bahwa "Protection must be optimized to provide the highest level of safety that can reasonably be achieved" [3].

Dalam makalah ini, disampaikan kaitan pemanfaatan QD untuk detektor sinar-X dalam upaya optimisasi proteksi radiasi. Dengan mempertimbangkan faktor detektor yang digunakan, diharapkan proteksi radiasi dapat lebih ditingkatkan sehingga dosis yang diterima baik oleh pasien, pekerja dan masyarakat dapat dibuat serendah mungkin dengan kualitas citra yang dapat diterima untuk diagnosis pasien.

\section{METODE}

Dalam kajian ini dilakukan pendekatan studi literatur terhadap pemanfaatan dan pengujian beberapa jenis QD sebagai detektor sinar-X. Dari beberapa jenis QD yang digunakan dalam literatur, akan dilihat perbandingan citra yang dihasilkan. Citra tersebut akan menunjukkan intensitas dari sinar-X yang dihasilkan oleh detektor tersebut.

Berkaitan dengan upaya optimisasi proteksi radiasi, akan diperoleh keterkaitan dari tingkat efisiensi detektor mengkonversi sinar-X menjadi cahaya tampak dengan upaya mengurangi dosis yang akan diterima oleh pasien, pekerja dan masyarakat. Untuk mengamati pengaruh jenis QD, maka ditampilkan hasil citra dari literatur yang diacu. Selain pengaruh jenis QD, citra yang dihasilkan dari proses penggabungan bahan fosfor dan QD juga ditampilkan. Dari perbandingan tersebut maka dapat dilakukan upaya optimisasi proteksi radiasi berdasarkan detektor yang digunakan pada sistem Radiografi Diagnostik.

\section{HASIL DAN PEMBAHASAN}

\section{Pengaruh Jenis Quantum Dot}

Pemilihan jenis Quantum Dot akan mempengaruhi efisiensi untuk mendeteksi radiasi pengion. Untuk mendeteksi sinar-X, pengujian telah dilakukan dengan membandingkan hasil deteksi antara Kadmium Telurida (CdTe) dengan Kadmium Selenida (CdSe) [7]. Hasil pengujian ditampilkan berupa citra pada Gambar 1. Pada citra sebelah kiri menunjukkan hasil pengujian menggunakan CdTe, sedangkan sisi sebelah kanan merupakan hasil pengujian menggunakan CdSe. Pengujian tersebut direkam dengan kamera CCD sehingga yang terekam adalah 
cahaya tampak yang dihasilkan akibat adanya interaksi antara sinar-X dengan QD [7]. Dengan citra yang menunjukkan warna lebih terang, mengindikasikan bahwa cahaya tampak yang dihasilkan oleh QD memiliki intensitas yang lebih tinggi. Pengujian tersebut menunjukkan bahwa CdTe menghasilkan intensitas cahaya tampak yang lebih tinggi jika dibandingkan dengan CdSe.

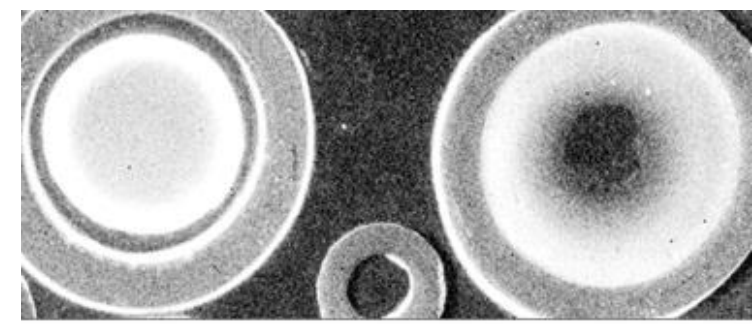

Gambar. 1. Citra intensitas cahaya tampak yang dihasilkan pada CdTe (kiri) dan CdSe (kanan) jika berinteraksi dengan sinar-X [7]

Hasil pada citra menunjukkan intensitas yang dipancarkan CdTe 87,53\% lebih tinggi dibandingkan dengan intensitas yang dipancarkan CdSe. Berdasarkan analisis profil derajat keabuan, diperoleh hasil seperti pada Gambar 2. Intensitas yang dihasilkan oleh QD mengindikasikan efisiensi dalam mendeteksi sinar-X. Hasil tersebut menunjukkan bahwa CdTe memiliki efisiensi mendeteksi sinar-X yang lebih baik dari CdSe [7]. Dengan adanya efisiensi yang tinggi berarti akan lebih banyak sinar-X yang dikonversi menjadi cahaya tampak. Sedangkan jika efisiensi rendah maka energi dari sinar-X sebagian dikonversi menjadi panas atau tidak terjadi interaksi.

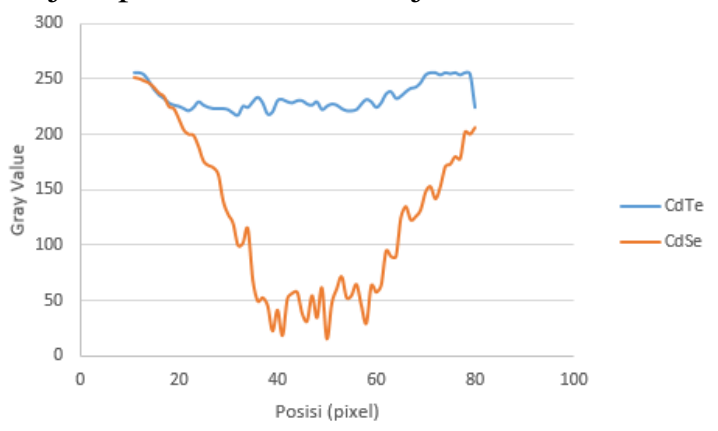

Gambar. 2. Profil derajat keabuan detektor CdTe dan CdSe

\section{Kombinasi QD dan Bahan Fosfor}

Metode lain yang dapat digunakan untuk meningkatkan efisiensi deteksi sinar- $\mathrm{X}$ adalah dengan kombinasi antara QD dengan bahan fosfor. Bahan fosfor yang digunakan pada sintilator untuk mengkonversi sinar-X menjadi cahaya tampak dapat ditinggkatkan efisiensinya dengan mengkombinasikan dengan QD [8]. Pengujian tersebut dilakukan dengan membandingkan cahaya tampak yang dihasilkan pada bahan fosfor dengan bahan yang mengandung fosfor dan QD. Dalam pengujian tersebut digunakan Polystyrene (PST) sebagai polimer yang berfungsi sebagai media untuk melekatkan bahan fosfor dan QD. Bahan fosfor yang digunakan adalah 2,5diphenyloxazole (PPO) sedangkan QD yang digunakan adalah CdZe/ZnS [8]. Gambar 3 menunjukkan perbandingan intensitas cahaya tampak yang dihasilkan dari PST/PPO dengan kombinasi PST/PPO/QDot. Hasil yang diperoleh menunjukkan bahwa intensitas yang dihasilkan dari kombinasi tersebut jauh lebih tinggi dibandingkan dengan hanya menggunakan bahan fosfor (PST/PPO). Selain itu, kombinasi tersebut memberikan intensitas yang lebih tinggi dibandingkan dengan hanya menggunakan QD (PST/QDot). Berdasarkan analisis citra yang dihasilkan, diperoleh bahwa intensitas yang dihasilkan oleh PST/PPO/QDot lebih tinggi 101,4\% dibandingkan dengan intensitas dari citra PST/QDot. Selain itu, intensitas PST/PPO/QDot jauh lebih tinggi yakni $250 \%$ dari intensitas PST/PPO. Hasil ini memberikan informasi bahwa dengan melakukan kombinasi tersebut, efisiensi konversi sinar-X menjadi cahaya tampak menjadi lebih tinggi dibandingkan hanya menggunakan salah satunya (fosfor maupun QD).

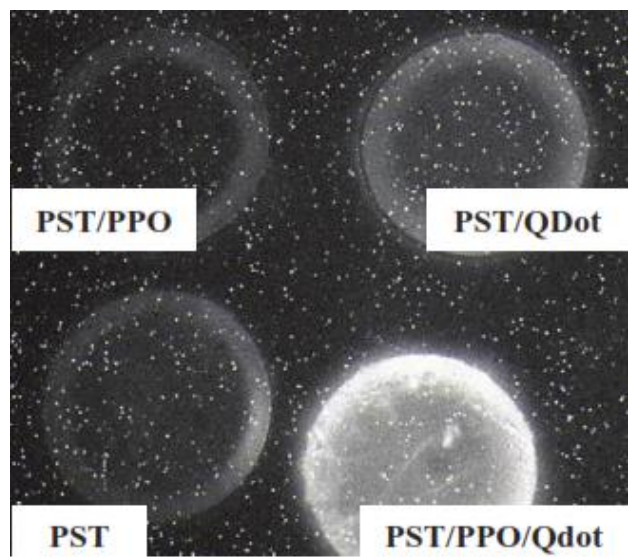

Gambar. 3. Citra intensitas cahaya tampak yang dihasilkan pada PST/PPO, PST/QDot, PST dan PST/PPO/QDot [8] 
Kondisi tersebut terjadi karena tidak semua proses serapan dikonversi menjadi cahaya tampak pada PPO, namun sebagian energinya diubah menjadi panas ataupun dalam bentuk lainnya. Energi tersebut yang dimanfaatkan sehingga terjadi eksitasi pada QD yang kemudian menyebabkan munculnya deeksitasi yang disertai pelepasan energi dalam bentuk cahaya tampak. Dengan adanya kombinasi dengan QD, intensitas cahaya tampak yang dihasilkan akan meningkat dari sebelumnya.

\section{Upaya Optimasi Proteksi Radiasi dalam Pemanfaatan Quantum Dot}

Melalui penjelasan terkait pemilihan bahan untuk detektor dan adanya kombinasi antara QD dengan bahan fosfor, diperoleh informasi adanya perbedaan intensitas yang dihasilkan baik pada variasi jenis QD maupun dengan adanya kombinasi antara QD dan bahan fosfor. Dengan memperhatikan faktor detektor tersebut, dapat dinyatakan bahwa fungsi detektor sangat mempengaruhi kualitas citra hasil penyinaran.

Selama ini, intensitas sinar- $X$ yang dipancarkan dari tabung sinar- $\mathrm{X}$ diatur dalam pengaturan arus filamen (mA). Sehingga semakin tinggi $\mathrm{mA}$ yang digunakan maka intensitas yang dihasilkan akan semakin tinggi pula. Namun perlu diperhatikan bahwa dalam pengaturan tersebut, tingkat efisiensi detektor dalam mengkonversi sinar- $X$ menjadi cahaya tampak sangat mempengaruhi kualitas citra radiograf yang dihasilkan. Hal ini berarti jika $\mathrm{mA}$ yang sama digunakan pada detektor dengan efisiensi yang berbeda, maka kualitas citra yang dihasilkan akan berbeda. Jika efisiensi semakin tinggi, maka dengan $\mathrm{mA}$ yang sama akan diperoleh citra yang lebih cerah dibandingkan dengan hasil pada detektor dengan efisiensi yang rendah. Jika mengacu dari literatur terkait pemanfaatan QD sebagai detektor sinar-X, maka dapat dilakukan optimisasi proteksi radiasi dengan memperhatikan detektor yang digunakan.

Jika digunakan detektor dengan bahan QD yang tepat terhadap rentang energi sinar-X yang digunakan, maka intensitas cahaya tampak yang dihasilkan oleh QD akan tinggi. Atau, jika dilakukan kombinasi QD-fosfor maka intensitas cahaya tampak yang dihasilkan akan tinggi. Dengan kedua kondisi tersebut, akan memungkinkan untuk dilakukan penurunan nilai $\mathrm{mA}$ pada sistem radiografi diagnostik. Dapat dianalogikan seperti kasus berikut, jika penyinaran dilakukan dengan menggunakan arus filamen $50 \mathrm{~mA}$ pada detektor dengan efisiensi sedang, maka jika digunakan detektor QD yang tepat atau kombinasi QD-fosfor yang memiliki efisiensi lebih tinggi, maka citra yang dihasilkan dari detektor tersebut akan lebih terang. Hal ini menyebabkan kualitas citra menjadi kurang baik untuk keperluan diagnosis karena citra yang dihasilkan terlalu cerah sehingga menyulitkan untuk melakukan diagnosis. Maka, perlu dilakukan penurunan nilai mA pada detektor tersebut sehingga citra yang dihasilkan menjadi tidak terlalu terang dan dapat dibaca untuk keperluan diagnosis. Hal ini berarti dengan dilakukannya penurunan nilai $\mathrm{mA}$ untuk memperoleh citra yang lebih baik maka dosis yang diterima oleh pasien, maupun pekerja dan masyarakat akan lebih rendah karena intensitas sinar- $\mathrm{X}$ yang dipancarkan lebih rendah dibandingkan pada penyinaran menggunakan detektor awal.

Kondisi tersebut menunjukkan bahwa dengan meningkatkan efisiensi dari detektor yang digunakan, maka dosis radiasi yang dibutuhkan untuk penyinaran akan semakin rendah sehingga optimisasi proteksi radiasi dapat dilakukan dan juga pemanfaatan radiasi pengion untuk keperluan diagnostik di bidang medis mampu memberikan manfaat yang jauh lebih besar dibandingkan dengan risikonya karena telah dilakukan pengurangan dosis akibat dari peningkatan efisiensi konversi sinar-X pada detektor yang digunakan. Hal ini tentu akan menunjang keselamatan radiasi seperti yang tertuang pada Perka BAPETEN Nomor 8 Tahun 2011 tentang Keselamatan Radiasi dalam Penggunaan Pesawat Sinar-X Radiologi Diagnostik dan Intervensional. Dalam Pasal 36 Ayat (1) disebutkan bahwa "Penerapan optimisasi proteksi dan keselamatan radiasi harus diupayakan agar Pekerjaan Radiasi di Instalasi Radiologi dan anggota masyarakat di sekitar Instalasi Radiologi menerima Paparan Radiasi serendah mungkin yang dapat dicapat. Dalam Ayat (2) disebutkan bahwa "Penerapan optimisasi proteksi dan keselamatan radiasi harus diupayakan agar pasien menerima Dosis Radiasi serendah mungkin sesuai dengan yang 
diperlukan untuk mencapat tujuan diagnostik" [9]. Dengan memperhatikan isi dari Perka BAPETEN Nomor 8 Tahun 2011 pada Pasal 36 Ayat (1) dan (2), maka pemanfaatan QD baik sebagai detektor langsung maupun kombinasi antara QD-fosfor dapat mengarahkan pada upaya optimisasi proteksi radiasi sehingga dosis yang diterima baik oleh pasien, pekerja dan masyarakat dapat diupayakan serendah mungkin.

\section{KESIMPULAN}

Dalam penerapan sistem radiografi untuk keperluan diagnostik, detektor fosfor menjadi bagian penting karena dapat mengkonversi sinar-X menjadi cahaya tampak sehingga pembacaan diagnosis dapat dilakukan pada kertas film. Namun bahan fosfor bukanlah satu-satunya yang dapat melakukan hal tersebut. QD yang merupakan bagian dari semikonduktor juga dapat mengkonversi sinar$\mathrm{X}$ menjadi cahaya tampak. Dengan pemilihan QD yang sesuai dengan rentang energi sinar-X, maka dapat diperoleh tingkat efisiensi yang tinggi sehingga intansitas cahaya tampak yang dihasilkan juga tinggi. Selain itu, dapat dilakukan kombinasi QD-fosfor sehingga sebagian energi de-eksitasi yang diubah menjadi panas atau energi lainnya dapat dimanfaatkan untuk mengeksitasi QD sehingga dalam proses de-eksitasi tersebut akan disertai dengan pancaran cahaya tampak. Hal ini akan meningkatkan intensitas cahaya tampak yang dihasilkan. Dengan adanya peningkatan efisiensi tersebut, dapat mendukung optimisasi proteksi radiasi karena intensitas sinar-X yang dipancarkan dapat lebih rendah berkaitan dengan efisiensi detektor yang tinggi. Maka, dosis yang diterima oleh pasien, pekerja dan masyarakat dapat dioptimalkan serendah mungkin sehingga pemanfaatan radiografi untuk keperluan diagnosis memberikan manfaat yang jauh lebih besar dibandingkan dengan risiko yang ditimbulkan.

\section{DAFTAR PUSTAKA}

1. Chan, W.C.W., Maxwell, D.J., Gao, X., Bailey, R.E., Han, M. and Nie, S., "Luminescent Quantum Dots for Multiplexed Biological Detection and Imaging”, Curr. Opin. Biotech., vol. 13 (1), pp. 40-46, 2002.
2. Gao, X., Yang, L., Petros, J.A., Marshall, F.F., Simons, J.W. and Nie, S., "In Vivo Molecular and Cellular Imaging with Quantum Dots", Curr. Opin. Biotech., vol. 16 (1), pp. 63-72, 2005.

3. IAEA Safety Standards, Fundamental Safety Principles No. SF-1, International Atomic Energi Agency, 2006.

4. IAEA Safety Standards, Radiation Protection and Safety of Radiation Sources: International Basic Safety Standards No. GSR Part 3, International Atomic Agency, 2014.

5. Isnaeni and Cho, Y.H.,, "The Fabrication and Characterization of Quantum DotsConjugate Opal Photonic Crystals Structure", Nanotechnology, vol. 21, pp. 225201, 2010.

6. Jamieson, T., Bakhshi, R., Petrova, D., Pocock, R., Imani, M. and Seifalian, A.M., "Biological Applications of Quantum Dots", Biomaterials, vol. 28, pp. 47174732, 2007.

7. Kang, Z., Zhang, Y., Menkara, H., Wagner, B.K., Summers, C.J., Lawrence, W. dan Nagarkar, V., "CdTe Quantum Dots and Polymer Nanocomposites for $\mathrm{X}$ Ray Scintillation and Imaging", Appl. Phys. Lett., vol. 98, pp. 181914, 2011.

8. Lawrence, W.G., Thacker, S., Palamakumburam S., Riley, K.J. and Nagarkar, V.V., "Quantum Dot - Organiic Polymer Composite Materials for X-Ray Detector and Imaging", IEEE Nuclear Science Symposium \& Medical Imaging Conference, pp. 246-252, 2010.

9. Peraturan Kepala BAPETEN Nomor 8 Tahun 2011 tentang Keselamatan Radiasi Dalam Penggunaan Pesawat Sinar-X Radiologi Diagnostik dan Intervensional, Badan Pengawas Tenaga Nuklir, 2011. 
JURNAL FORUM NUKLIR (JFN) VOLUME 12, NOMOR 2, NOVEMBER 2018 